\title{
EXPERIMENTAL DEMONSTRATION OF A TERAHERTZ EXTENDED INTERACTION OSCILLATOR DRIVEN BY A PSEUDOSPARK-SOURCED SHEET ELECTRON BEAM
}

${ }^{1}$ G. X. Shu, ${ }^{2}$ L. Zhang, ${ }^{2}$ H. Yin, ${ }^{2}$ J. P. Zhao, ${ }^{2}$ A. D. R. Phelps, ${ }^{2}$ A. W. Cross, ${ }^{3}$ G. Liu, ${ }^{3}$ Y. Luo, ${ }^{1}$ Z. F. Qian, and ${ }^{2}$ W. He ${ }^{1}$ College of Electronic Science and Technology, Shenzhen University, Shenzhen, 518060,

\section{China}

${ }^{2}$ Department of Physics, SUPA, University of Strathclyde, Glasgow, G4 ONG, UK

${ }^{3}$ School of Physical Electronics, University of Electronic Science and Technology of China, Chengdu, 610054, China

We have recently proposed to combine the advantages of a pseudospark-sourced sheet electron beam (PS-SEB) with a planar slow wave structure to generate high power terahertz radiation. To verify this idea, experimental investigation of an extended interaction oscillator based on the PS-SEB has been conducted and presented. A PS-SEB of approximately 1.0 $\mathrm{mm} \times 0.17 \mathrm{~mm}$ in size with $21.5 \mathrm{~A}$ peak current $\left(1.26 \times 10^{4} \mathrm{~A} / \mathrm{cm}^{2}\right.$ beam current density) and $34.5 \mathrm{kV}$ peak voltage was measured after propagating a distance of $10-\mathrm{mm}$ without the need of an external focusing magnetic field. A radiation pulse of $\sim 35 \mathrm{~ns}$ in duration, and output power of over $10 \mathrm{~W}$ at a frequency of $\sim 0.2 \mathrm{THz}$ was measured. 
High power radiation sources in the terahertz $(\mathrm{THz})$ regime $(0.1-10 \mathrm{THz})$ are required for various applications including non-invasive sensing of concealed contraband, high-data-rate communications, high resolution radar, material science and spectroscopy. ${ }^{1-2}$ Vacuum electronic devices (VEDs) have been widely studied as promising $\mathrm{THz}$ radiation sources because of their high electronic efficiency, high power capacity and room-temperature operation..$^{2-11}$ When extending to $\mathrm{THz}$ frequencies, the radiation power of typical VEDs based on a thermionic cathode electron gun will be greatly reduced due to the small beam current that can be propagated down through a beam wave interaction structure of diameter typically on the order of the wavelength of operation. The limited beam current is mainly due to the restriction in the electron emission current density from thermionic emitters and the electron beam interception. Other factors such as the increase in ohmic losses as the frequency increases conspires to further reduce the output power of the device.

Several approaches are proposed to alleviate these two aforementioned problems. ${ }^{12}$ Firstly, to reduce the power loss in the interaction circuit, an extended interaction oscillator (EIO) was studied as its resonant slow wave structure (SWS) can be short in the order of only a few wavelengths long because of the high gain per unit length. ${ }^{5-7}$ Secondly, to increase the beam current, a pseudospark-sourced sheet electron beam (PS-SEB) is employed to drive the resonant SWS. According to the experimental results of various pseudospark discharge systems, the PS-EB has much higher beam current density $\left(>10^{4} \mathrm{~A} / \mathrm{cm}^{2}\right)$ than the beam generated by a thermionic cathode, and it can be confined by an ion-focusing channel generated by the system itself. ${ }^{8-15}$ A sheet electron beam is very attractive due to its enlarged beam cross section area and reduced space charge effect, however the focusing and formation of a sheet electron beam is challenging especially when the beam has to be propagated down through a THz structure of small transverse cross-section. ${ }^{16-21}$ A very high current electron beam capable of being transported through a $\mathrm{THz}$ interaction circuit can be realized by 
combining the advantages of the PS-EB and the sheet electron beam geometry. Detailed analysis and design regarding this EIO has been presented in our early work ${ }^{12}$, and this letter will focus on the experimental demonstration.

As shown in Fig. 1, the EIO was composed of a PS-SEB system and an interaction circuit. The PS-SEB system consisted of a pseudospark discharge section and a post-acceleration gap $^{22}$. It was composed of a brass hollow cathode with a cylindrical cavity of $26 \mathrm{~mm}$ in diameter and $12 \mathrm{~mm}$ in length, a perspex insulator of $16 \mathrm{~mm}$ thickness, a brass postacceleration electrode, a perspex insulator of $6 \mathrm{~mm}$ thickness and a brass planar anode, resulting in the formation of a pseudospark discharge section and a post-acceleration gap. The generated pencil PS-EB would propagate from the hollow cavity to the anode through an onaxis aperture of $3 \mathrm{~mm}$ diameter. At the anode a rectangular collimator with the size of 2.0 $\mathrm{mm} \times 0.25 \mathrm{~mm}$ was used to form the PS-SEB. There are three main stages in a typical pseudospark discharge, where a PS-EB with moderate beam current and high energy can be obtained in the second hollow cathode stage (used for the beam-wave interaction in reference $5,10-11)$. The beam current reaches its maximum in the third pseudospark discharge stage, while the beam energy rapidly decreases due to the breakdown between the gaps. Postacceleration of the PS-EB generated in the third stage could result in combined high beam current and energy (the most desirable electron beam for the beam-wave interaction), which was implemented in this work by insertion of a post-acceleration electrode and a $200 \Omega$ high voltage resistor $R_{2}$. The experiment of the post-acceleration related to this PS-SEB was reported in reference 23 .

To match and interact with the PS-SEB, a planar EIO circuit was used in our design. It had the advantage that it could be machined by wire-cutting technology. The interaction circuit was composed of a resonant SWS (including a rectangular beam tunnel, two coupling cavities 
and eleven gaps) and an output coupling structure (consisting of a coupling waveguide and an output waveguide).

To achieve a stable gas pressure, a rotary pump was used to evacuate the tube and the operating gas (air in this case) entered the whole system through a fine adjustable needle valve. The gas pressure was monitored by a vacuum gauge. A cylindrical aperture of $2 \mathrm{~mm}$ diameter was drilled at the end of the interaction circuit to generate an exhaust path leading to the drift tube. A standard rectangular waveguide WR-5 was connected to the interaction circuit's output waveguide, with the vacuum seal achieved by the use of a thin Mylar sheet placed between them. A cylindrical tube filled with the interaction circuit was integrated with the PS-SEB system using an "O” ring, thus achieving a complete EIO.

The expense for making a PS-SEB driven EIO was relatively low, due to some of its advantages, such as the ease of fabrication of the device, low vacuum requirement and the fact that an external focusing magnetic field would not be required. The PS-SEB system had relatively large structural dimensions and its smallest part (the $3 \mathrm{~mm}$ cylindrical aperture) had the property of axial symmetry enabling it to be manufactured easily by using a milling machine. The fabrication challenge of the whole device was mainly due to the construction of the interaction circuit. The optimized structural dimensions in reference 12 were used in our experiment. It should be noted, to ease the fabrication using the electric discharge machining, that the coupling waveguide in reference 12 was not used, instead the standard output waveguide was directly connected to the resonant SWS, which would reduce the coupling efficiency and thus result in a smaller measured radiation power. As shown in Fig. 2, the interaction circuit has been divided into three parts. Part 1 and part 2 were fabricated by high speed milling and the two rectangular waveguides in part 2 were first drilled with the final geometry achieved by electrical discharge machining. The beam tunnel and eleven gaps in part 3 were wire cut from a piece of copper block in one process (using tungsten wire of 
diameter $30 \mu \mathrm{m})$. The assembled interaction circuit had a compact configuration with 3-D dimensions of $28 \mathrm{~mm} \times 17 \mathrm{~mm} \times 5 \mathrm{~mm}$. The reflection coefficient curve $\left(S_{11}\right)$ was measured using a vector network analyzer (Anritsu 37397D) and a frequency extender (Anritsu V05VNA2-T/R 140-220 GHz), and was in agreement with the simulation prediction ${ }^{12}$. The operating mode (TM110-2 $\pi$ mode) had a resonant peak at $\sim 197.8 \mathrm{GHz}$.

The schematic diagram of the EIO experimental setup and a photo of the experimental setup are shown in Fig. 3(a) and (b), respectively. The pseudospark discharge chamber combined with the post-acceleration section is powered by a high voltage pulse generated from a pulse forming network (PFN), which was composed of a $\mathrm{LC}$ circuit ${ }^{23}$. The PFN was connected to a negative high voltage DC power supply through a $10 \mathrm{M} \Omega$ charging resistor $R_{1}$ and a high voltage switch. A trigger was introduced between the PFN and the hollow cathode to provide the seed electrons to start the pseudospark discharge ${ }^{23}$.

When a high voltage pulse was applied to the PS-SEB system and a moderate gas pressure $(0-10 \mathrm{~Pa}$ in the experiment) was reached, most of the voltage will initially drop on the trigger gap, then the pseudospark gap and finally the post-acceleration gap. Correspondingly, these three gaps would breakdown in sequence. After the breakdown in the pseudospark gap, most of the discharge voltage would drop on the post-acceleration gap and $R_{2}$, thus the electron beam with high current but low energy could be post-accelerated. The discharge process was described in references 10 and 22 .

To capture the PS-SEB's shape, a rectangular collimator of $10 \mathrm{~mm}$ thickness was placed in contact with the anode plate. A scintillator disk of $8 \mathrm{~mm}$ diameter made from a $50 \mu \mathrm{m}$ thick copper foil coated with scintillation powder (Plano P47) was placed at the end of the collimator. As shown in Fig. 4(a), a collimator with a $2 \mathrm{~mm} \times 0.25 \mathrm{~mm}$ rectangular aperture (the same size as the beam tunnel) was wire cut from a cylindrical brass block of $10 \mathrm{~mm}$ thickness, which is chosen to be longer than the interaction circuit of $5.6 \mathrm{~mm}$. It was made by 
wire cutting from the edge of the circular brass block and a long slot was thus formed, which ensured good gas flow and kept the gas pressure uniform in the device. When the PS-SEB hits the copper foil of the scintillator, the low energy electrons and any radiation generated by the discharge as well as any X-rays would be blocked, but the electrons with high energy will penetrate the foil and stimulate the scintillation powder and further generate light, thus the electron beam profile could be measured. The electron beam images were captured using a digital camera (Nikon D50) remotely controlled by a computer. As shown in Fig. 4(b), the obtained electron beam image was an "L" shape, which corresponds to the profile of the wire cut path. By removing the part corresponding to the long slot, a rectangular shape with cross section of $1.0 \mathrm{~mm} \times 0.17 \mathrm{~mm}$ was observed.

Two high voltage probes (1000:1 Tektronix P6015A) were used to measure the high voltages on the cathode $V_{\mathrm{p} 1}$ and the post-acceleration electrode $V_{\mathrm{p} 2}$, which were both connected to an oscilloscope (Tektronix TDS 640). To measure the beam current, a Rogowski coil was located at the end of the collimator. A $10 \Omega$ resistor $R_{\mathrm{s}}$ was used to convert the beam current to a voltage signal, which was monitored by the same oscilloscope. Fig. 5(a) presents the time-correlated electron beam current and the total discharge voltage and post-acceleration voltage. For the correct background pressure the measured discharge voltage, post accelerating voltage and beam current were reproducible on a pulse-to-pulse basis. The $V_{\mathrm{p} 1}$ pulse has a pulse width of $150 \mathrm{~ns}$ and amplitude of $>34 \mathrm{kV}$, and the maximum amplitude of the $V_{\mathrm{p} 2}$ pulse is $34 \mathrm{kV}$. The $V_{\mathrm{p} 2}$ pulse has a smaller pulse width, indicating that the PS-EB's post-acceleration worked well. The beam current of $>10$ A had a pulse duration of $60 \mathrm{~ns}$, and the maximum electron beam current was up to $21.5 \mathrm{~A}$, corresponding to a current density of $\sim 1.26 \times 10^{4} \mathrm{~A} / \mathrm{cm}^{2}$. Due to the use of post-acceleration, the obtained PS-SEB has a combined high current of $>6 \mathrm{~A}$ and beam energy of $>30 \mathrm{keV}$, as shown in Fig. 5(a). 
As illustrated in Fig. 3, a G-band horn was connected to the standard rectangular waveguide to extract the radiation generated by the EIO. To receive the radiated $\mathrm{THz}$ signal, an identical horn was placed adjacent to the transmitting horn with a separation distance of 5 $\mathrm{cm}$. An adjustable attenuator ( $5 \mathrm{~dB}$ in this experiment) was used so as to ensure the power entering into the semiconductor rectifying diode (ELVA-1 Microwave Ltd., ZBD-05, 140-220 GHz) was below its damage threshold. The detected signal was then recorded by an oscilloscope (Tektronix TDS 640). To calibrate the detector, the EIO was replaced by a solidstate source with all other diagnostics remaining unchanged. The time-correlated voltage traces were recorded with different input power levels and different separation distances between the pair of horns, which then enabled an estimation of the radiation power. To gauge the THz-wave's frequency range, a sequence of cutoff filters (cylindrical waveguides) with different sizes were used. If the detected signal appeared using one cutoff filter, but disappeared when replaced by the next one, then it could be confirmed that the radiated frequency lies in that cutoff frequency range. To prevent the external electromagnetic interference due to noise generated from the pulsed power system; the receiving horn, adjustable attenuator, cutoff filter and detector were all placed in a metal shielding box. As shown in Fig. 5(b), the radiation pulse was recorded when a filter with a cutoff frequency of $197 \mathrm{GHz}$ was used. For comparison the radiation pulse almost disappeared when a $199 \mathrm{GHz}$ cutoff filter was used. The sensitivity of the detector at $\sim 200 \mathrm{GHz}$ was carefully calibrated to be $1 \mathrm{mV} / \mathrm{mW}$. Through the integration of the received radiation power over the radiation field pattern it was estimated that the output power was $\sim 10 \mathrm{~W}$ with a FWHM (full width half maximum) pulse width of $\sim 35 \mathrm{~ns}$ in the radiation frequency range of 197-199 GHz.

The measured output power is much smaller than that of the simulated output power in the optimized model in reference 12. The fabricated output coupling structure was different from that of the optimized model. Simulations show that the use of the standard output waveguide 
almost halves the output power. As discussed in reference 12, collisions between the beam electrons and the background gas increase the energy spread of the electron beam and reduce the 'effective' beam current, resulting in a large reduction in the radiation power. The beamwave interaction within the EIO is inherently a process of instability or bunching of the electron beam which could also greatly reduce the electron beam current. Furthermore the surface roughness of the fabricated interaction circuit results in a low intrinsic quality factor significantly reducing the radiation power. Taking into account these considerations, for example a simulation model of the fabricated interaction structure in which the 'effective' beam current, energy spread, and background material conductivity are assumed to be $1 \mathrm{~A}$, $15 \%$, and $\sigma_{\mathrm{Cu}} / 10\left(0.58 \times 10^{7} \mathrm{~S} / \mathrm{m}\right)$, respectively, predicts a radiation power of $\sim 80 \mathrm{~W}$.

In conclusion, a rectangular PS-SEB with combined high beam current and energy was obtained and the $\mathrm{THz}$ radiation pulse was generated and characterized. The experimental results have confirmed the proposed idea that it is feasible to combine the properties of a sheet electron beam generated by a pseudospark discharge system with that of a planar EIO structure. It is a significant advance and may contribute to future development of this kind of VED. Such a configuration provides a promising solution for compact, low cost, roomtemperature operation of high power $\mathrm{THz}$ radiation sources.

The authors would like to thank Mr David Barclay of the Atoms, Beams and Plasmas group at the Department of Physics, University of Strathclyde, UK for machining the components for the experiment. 
Figure list

Fig. 1 Schematic diagram of the EIO composed of a PS-SEB system and an interaction circuit.

Fig. 2 Three parts of the fabricated interaction circuit

Fig. 3 (a) Schematic diagram of the EIO experimental setup, including measurement of the voltage $V_{\mathrm{p} 1}$ and $V_{\mathrm{p} 2}$, beam current, beam shape and radiation pulse and (b) a photo of the EIO experimental setup for measuring $V_{\mathrm{p} 1}, V_{\mathrm{p} 2}$, and radiation pulse.

Fig. 4 The recorded beam image of a PS-SEB.

Fig. 5 Measured results (a) Time-correlated electron beam voltage and current pulse and (b) the $\mathrm{THz}$ radiation pulse and the noise signal. 


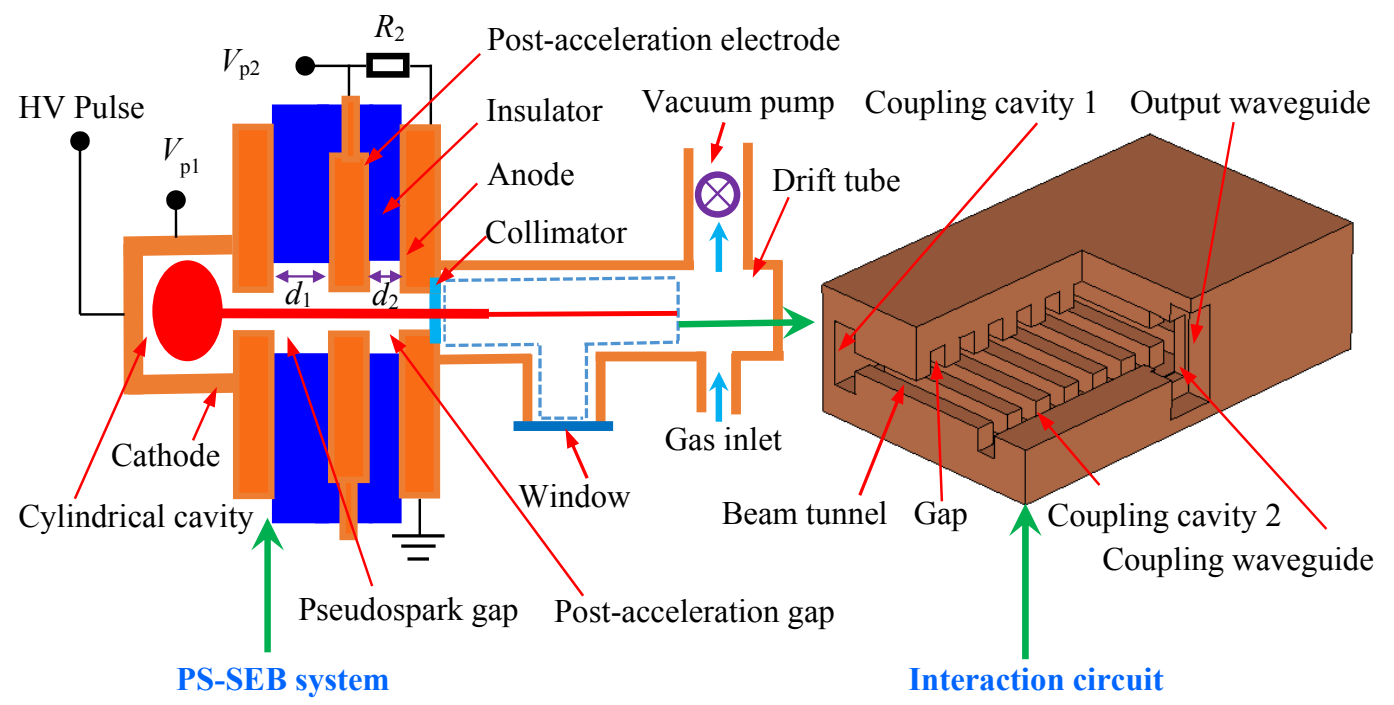

fig. 1 


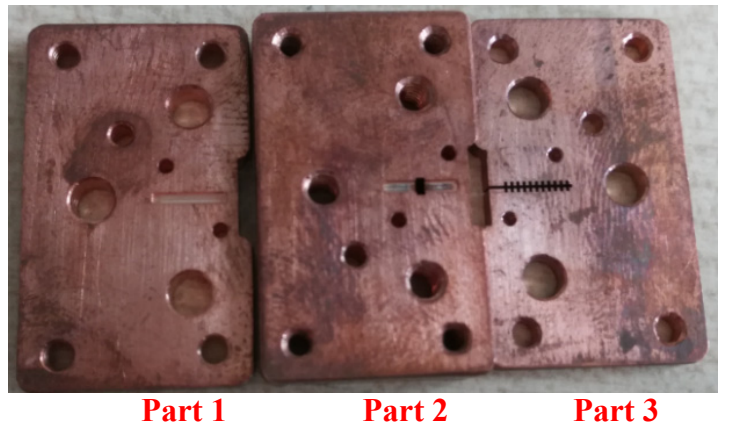

fig. 2 


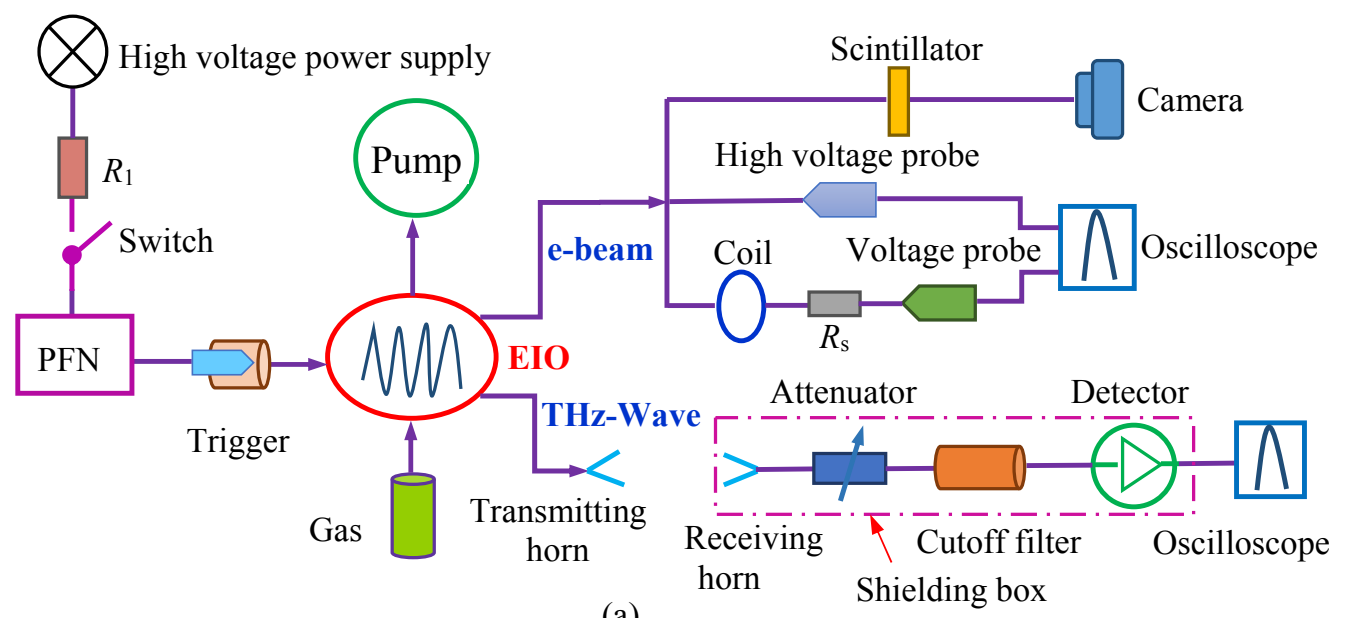

(a)

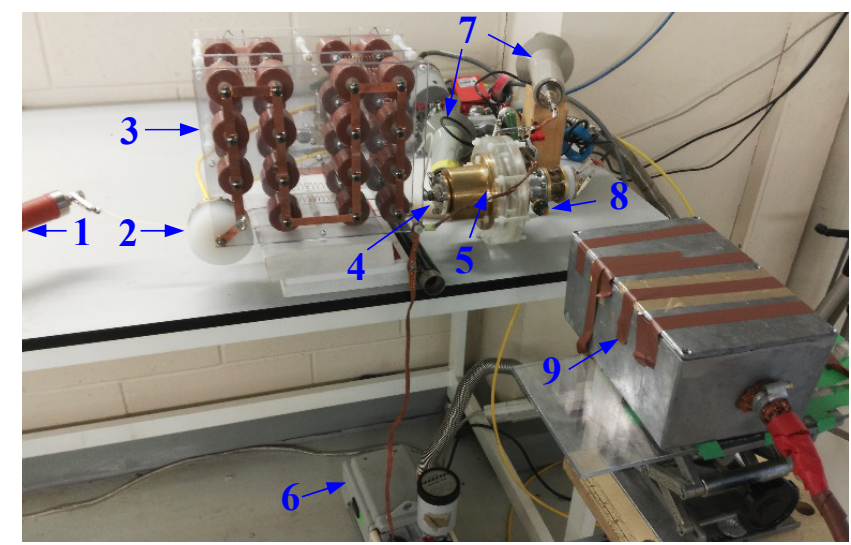

(b)
$1-R_{1}$

2-Switch

3-PFN

4-Trigger

5-EIO

6-Pump

7-High voltage probe

8-Transmitting horn

9-Shielding box

fig. 3 


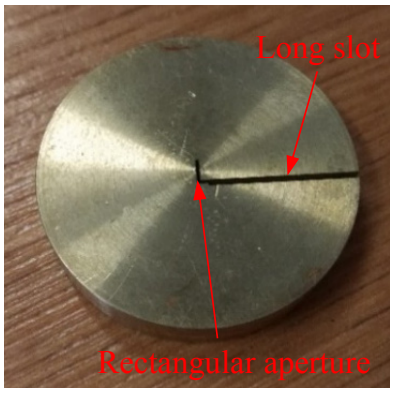

(a)

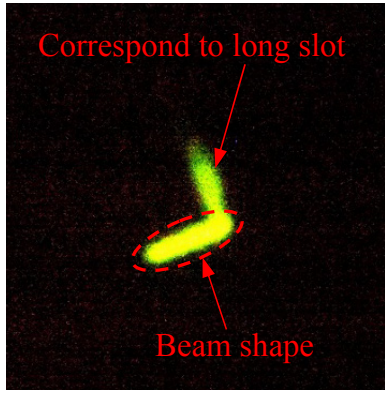

(b)

fig. 4 


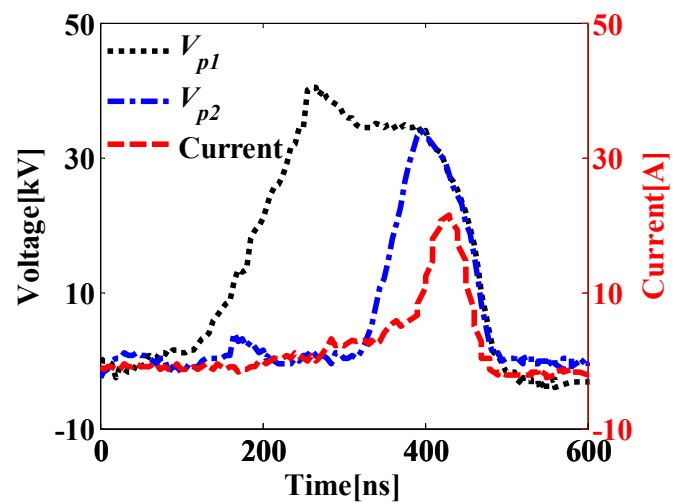

(a)

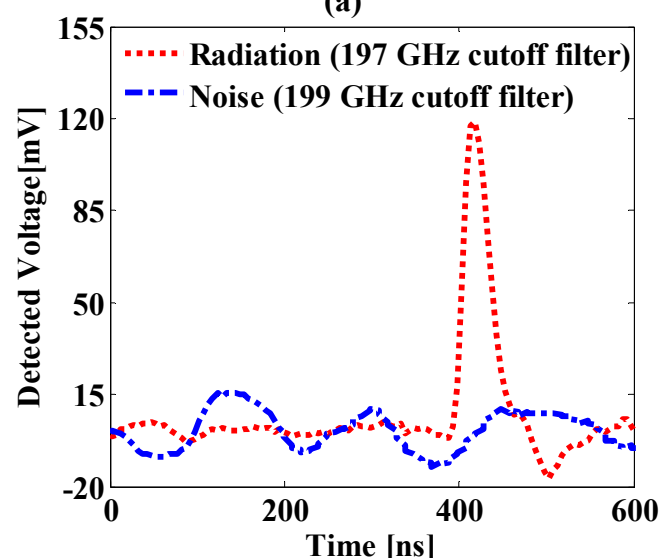

(b)

fig. 5 


\section{References}

${ }^{1}$ E. Linfield, Nature Photon.1, 257 (2007).

${ }^{2}$ J. H. Booske, R. J. Dobbs, C. D. Joye, C. L. Kory, G. R. Neil, G. S. Park, J. Park, and R. J. Temkin, IEEE Trans. Terahertz Sci. Technol. 1, 54(2011).

${ }^{3}$ J. H. Booske, Phys. Plasmas 15, 055502 (2008).

${ }^{4}$ C. W. Baik, H. Y. Ahn, Y. Kim, J. Lee, S. Hong, S. H. Lee, J. H. Choi, S. Kim, S. Y. Jeon, S. Yu, G. Collins, M. E. Read, R. L. Ives, J. M. Kim, and S. Hwang, Appl. Phys. Lett. 107, 191109 (2015).

${ }^{5}$ Y. Yin, W. He, L. Zhang, H. Yin, C. W. Robertson, and A. W. Cross, IEEE Trans. Electron Devices 63, 512 (2016).

${ }^{6} \mathrm{P}$. Horoyski, A. Roitman, R. Dobbs, M. Hyttinen, H. Deng, 15th IEEE International Vacuum Electronics Conference (2014), pp. 221-222.

${ }^{7}$ W. X. Liu, C. Zhao, K. Li, Y. Wang, Z. Q. Yang, IEEE Trans. Electron Devices 61, 902 (2014).

${ }^{8}$ J. Christiansen and C. Schultheiss, Z. Phys. A 290, 35 (1979).

${ }^{9}$ W. W. Destler, Z. Segalov, J. Rodgers, K. Ramaswamy, and M. Reiser, Appl. Phys. Lett. 62, 1739 (1993).

${ }^{10}$ W. He, L. Zhang, D. Bowes, H. Yin, K. Ronald, A. D. R. Phelps, and A.W. Cross, Appl. Phys. Lett. 107, 133501 (2015).

${ }^{11}$ H. Yin, A. W. Cross, W. He, A. D. R. Phelps, K. Ronald, D. Bowes, and C. W. Robertson, Phys. Plasmas 16, 063105 (2009).

${ }^{12}$ G. Shu, W. He, L. Zhang, H. Yin, J. Zhao, A. W. Cross, and A. D. R. Phelps, IEEE Trans. Electron Devices 63, 4955 (2016).

${ }^{13}$ N. Kumar, D. K. Pal, R. P. Lamba, U.N. Pal and R. Prakash, IEEE Trans. Electron Devices 64, 2688 (2017).

${ }^{14}$ N. Kumar, D. K. Pal, A. S. Jadon, U. N. Pal, H. Rahaman and R. Prakash, Rev. Sci. Instr. 87, 033503 (2016).

${ }^{15}$ U. N. Pal, P. Shukla, A. S. Jadon, and N. Kumar, IEEE Trans. Plasma Sci., 99 (2017).

${ }^{16}$ C. Q. Jiang, A. Kuthi, M. A. Gundersen, and W. Hartmann, Appl. Phys. Lett. 87, 131501 (2005).

${ }^{17}$ A. Baig, D. Gamzina, T. Kimura, J. Atkinson, C. Domier, B. Popovic, L. Himes, R. Barchfeld, M. Field, N. C. Luhmann, Jr., IEEE Trans. Electron Devices 64, 2390 (2017). 
${ }^{18}$ Y. M. Shin, A. Baig, R. Barchfeld, D. Gamzina, L. R. Barnett, and N. C. Luhmann, Jr., Appl. Phys. Lett. 100, 154103 (2012).

${ }^{19}$ J. Pasour, E. Wright, K. T. Nguyen, A. Balkcum, F. N. Wood, R. E. Myers, B. Levush, IEEE Trans. Electron Devices 61, 1630 (2014).

${ }^{20}$ Z. X. Zhang, W. W. Destler, V. L. Granatstein, T. M. Antonsen, Jr., B. Levush, J. Rodgers, and S. Cheng. Appl. Phys. Lett. 64, 1439 (2009).

${ }^{21}$ M. Mineo and C. Paoloni, IEEE Trans. Electron Devices 57, 1481 (2010).

${ }^{22}$ H. Yin, A. W. Cross, W. He, A. D. R. Phelps, and K. Ronald, IEEE Trans. Plasma Sci. 32, 233 (2004).

${ }^{23}$ J. Zhao, H. Yin, L. Zhang, G. Shu, W. He, Q. Zhang, A. D. R. Phelps, and A. W. Cross, Phys. Plasmas 24, 023105 (2017). 


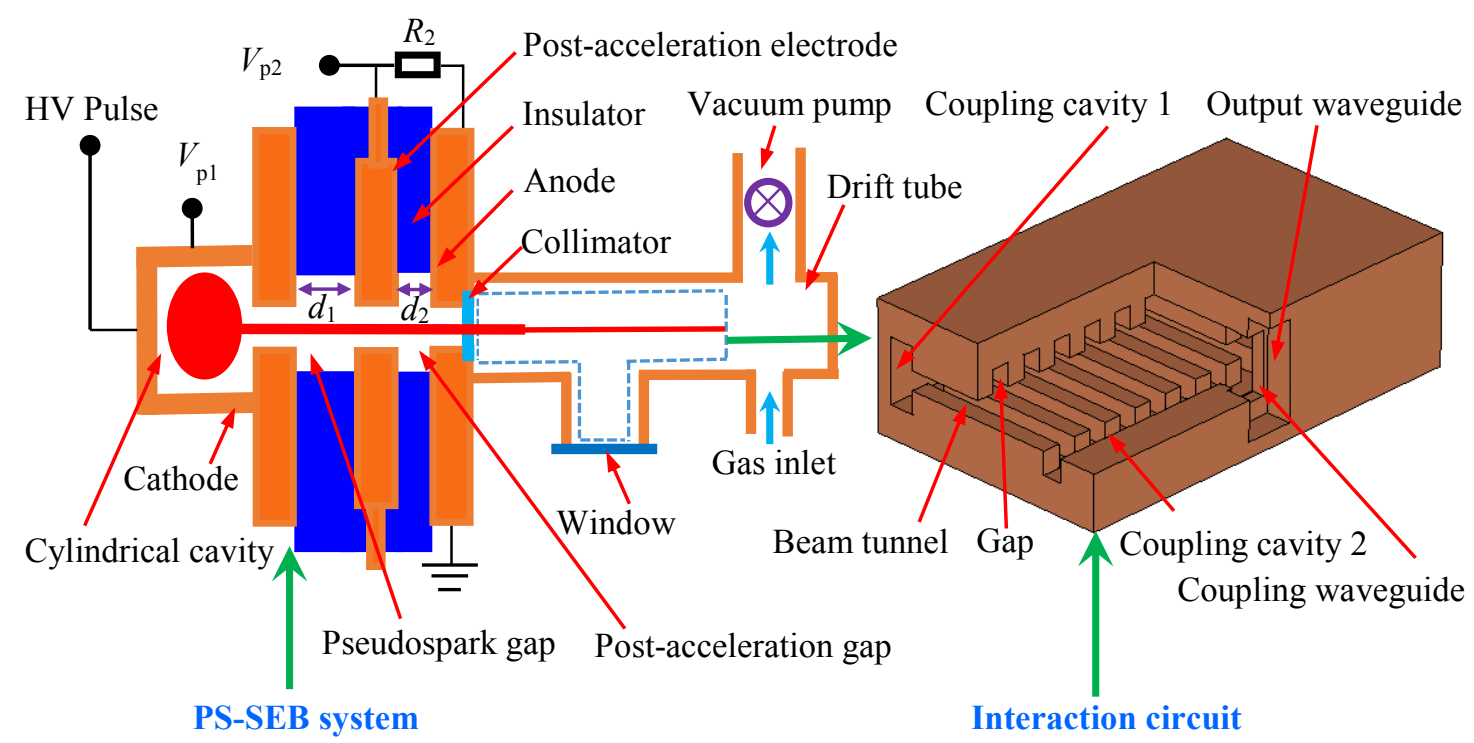




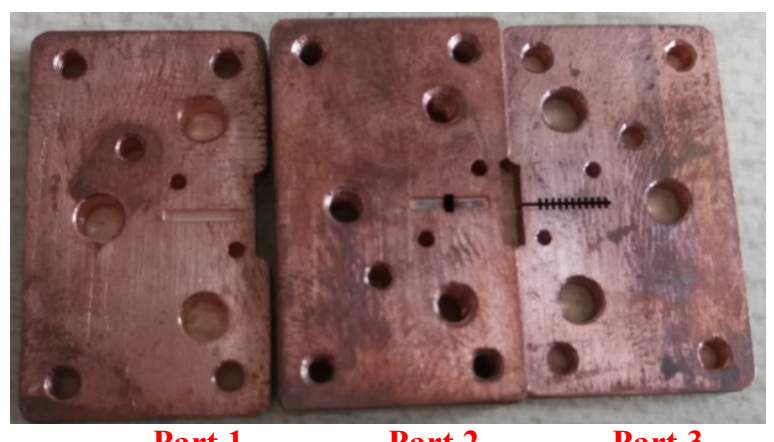

Part 1

Part 2

Part 3 


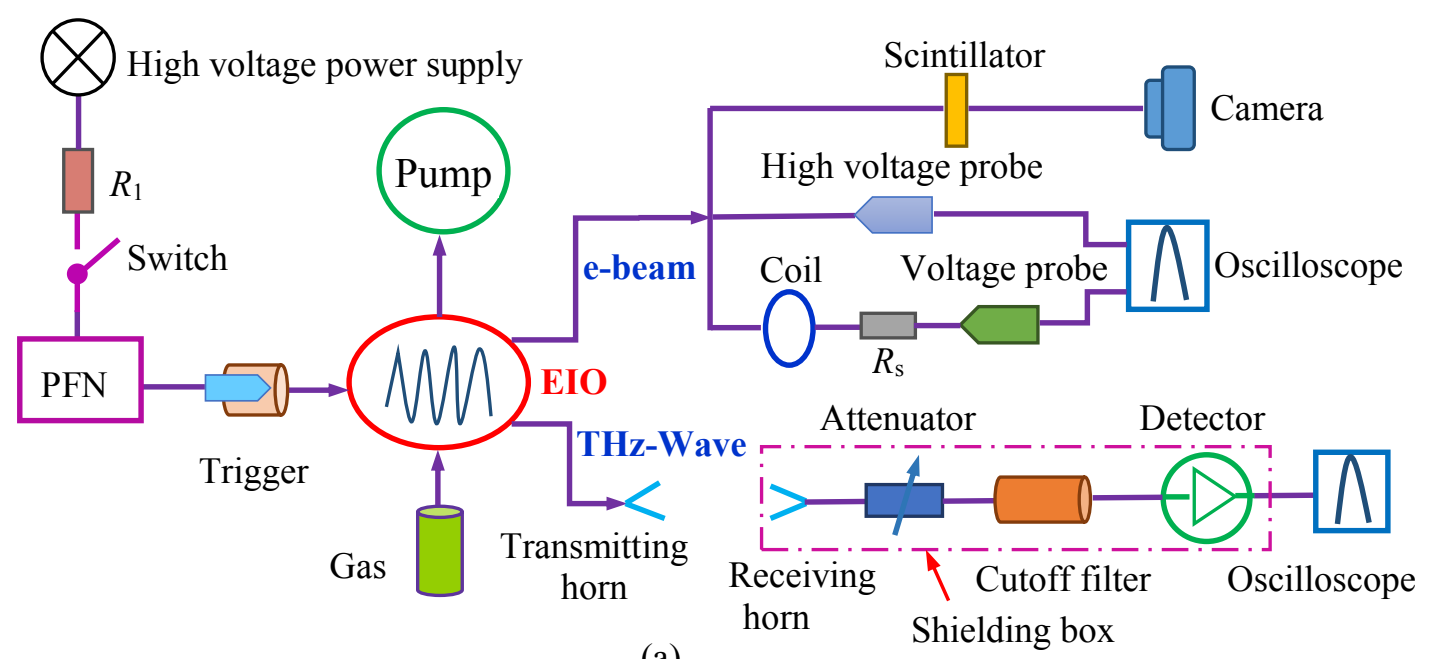

(a)

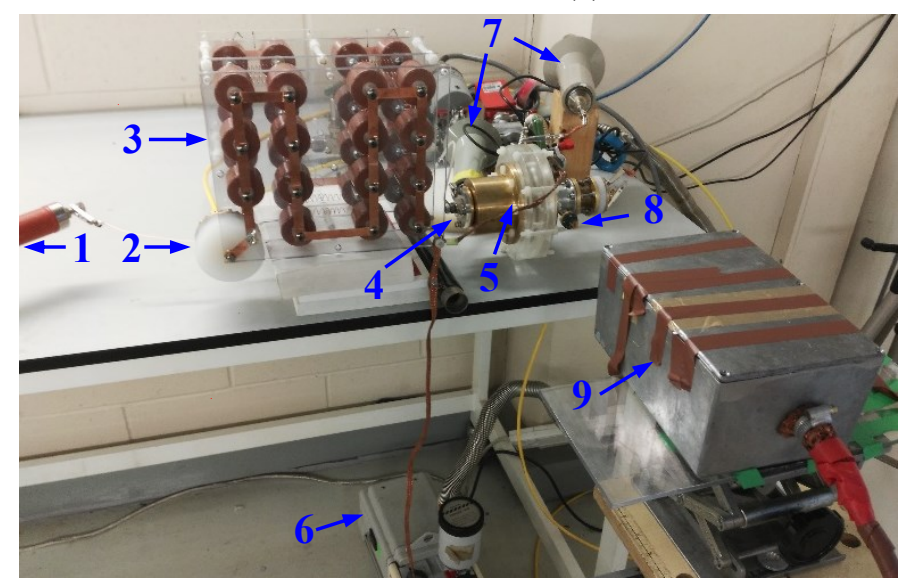

(b)
$1-R_{1}$

2-Switch

3-PFN

4-Trigger

5-EIO

6-Pump

7-High voltage probe

8-Transmitting horn

9-Shielding box 


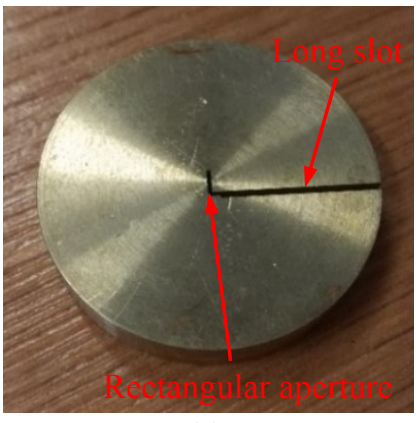

(a)

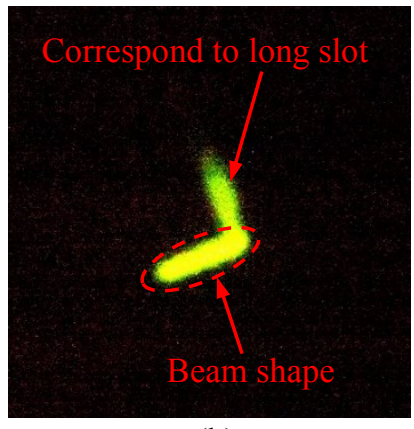

(b) 


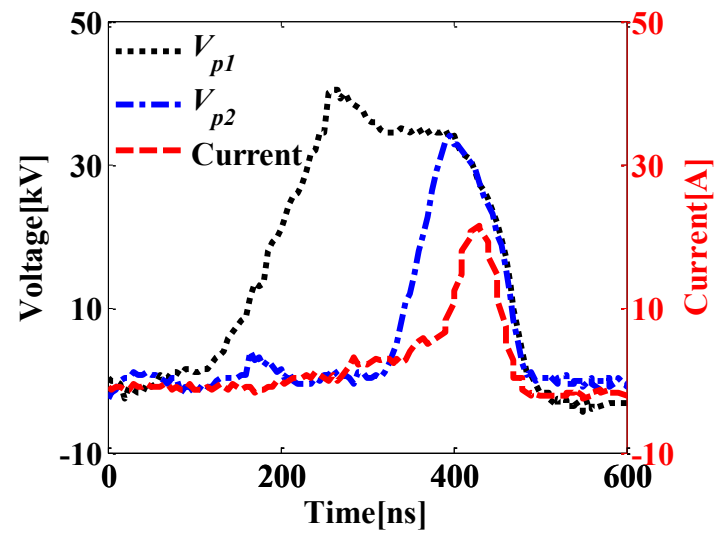

(a)

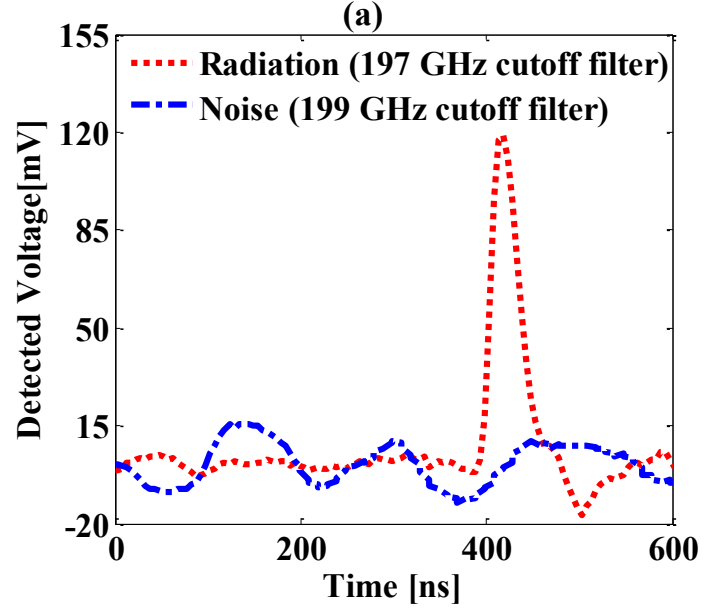

(b) 